\section{Ulcerated cutaneous epithelioid hemangioendothelioma in an 8-month old infant}

\author{
Silonie Sachdeva \\ Carolena Skin, Laser \& Research Centre \\ Jalandhar Punjab, India
}

\begin{abstract}
Epithelioid hemangioendothelioma is an uncommon malignant vascular tumour usually involving soft tissue and rarely only skin. It is considered to be a borderline neoplasm between angiolymphoid hyperplasia with eosinophilia and an epithelioid angiosarcoma and is mostly found in adults with few cases reported in children. We herein report a case of ulcerated cutaneous epithelioid hemangioendothelioma in an infant of 8 months. This tumour has not been reported at such a young age in literature.
\end{abstract}

\section{Introduction}

Epithelioid hemangioendotheliomas are unique vascular tumors characterized by epithelioid or histiocytoid endothelial cells that mainly affect adults. The tumor usually involves the soft tissue and, in rare cases, the skin. We report here a case of ulcerated cutaneous epithelioid hemangioendothelioma in an 8 month old infant. The tumor at such a young age has not been reported so far.

\section{Case Report}

An 8 month old male infant was brought by his parents with swelling on the left arm which appeared at the age of four months. There was history of oozing of blood and pus from the swelling. No predisposing factors for occurrence of lesion could be identified in history. There was no history of any accompanying systemic complaints. On dermatological examination, a well defined large swelling, round in shape, partly skin colored and partly dusky red in color with ulceration and exudation of the serosanguious fluid was seen on lateral aspect of left upper arm (Figure 1). Rest of the dermatological examination was normal. Axillary lymph nodes and cervical lymph nodes were not enlarged. Systemic examination revealed no abnormality. The infant's miles stones were normal as per his age.
A small biopsy was taken from the edge of the lesion. Histopathology revealed focal areas of infiltrative lobules of predominantly spindle cells in deeper dermis with small sized vascular channels lined by plump endothelial cells. There were foci of intravascular endothelial proliferation with the adjacent areas showing capillary proliferation with hobnail appearance (Figure 2). There was no cellular atypia, mitotic activity or necrosis suggestive of malignant activity. Immunohistochemical staining was positive for the endothelial markers CD31, CD34. MRI of the arm confirmed no underlying bone tumour. On the basis of these findings, diagnosis of ulcerated cutaneous epithelioid hemangioendothelioma was made. The infant was referred to the plastic surgery department for removal of tumor and reconstruction surgery. A conservative surgical excision with one centimeter margins all around the tumor was done. Patient is on follow up for last 6 months with no recurrence.

\section{Discussion}

Epithelioid hemangioendothelioma (EHE), first described by Weiss and Enzinger in the year 1982 , is an uncommon malignant vascular tumor which usually involves soft tissue and in rare cases the skin. Histologically and biologically it is considered to be a borderline neoplasm between angiolymphoid hyperplasia with eosinophilia and an epithelioid angiosarcoma. ${ }^{1,2}$ EHE affects men and women about equally at almost any age but rarely in childhood. No predisposing factors have been yet identified. Usually it appears as a solitary, slightly painful soft-tissue tumor which can occur at almost any anatomical location but more frequently on extremities, trunk, head and neck. In review of the literature, cutaneous EHE appears to be limited to a few reports in children and has been seen in age group ranging 11-12 years. ${ }^{3-5}$ In a series of 16 cases of islolated cutaneous EHE, the average age of tumor was found to be 47 years. All of these cases presented as dome-shaped nodules which are sometimes painful and can have a multifocal distribution. The main locations are the extremities (25\% on the palms), the head and the trunk. Our case is the first case report of ulcerated cutaneous EHE in an infant as young as 8 months.

EHE has malignant potential and its prognosis remains uncertain. Nevertheless, the prognosis of isolated cutaneous EHE after simple complete surgical excision seems good compared with systemic EHE or with cutaneous EHE with underlying bone tumor. ${ }^{7}$ In our patient, the tumor was benign as histopathology ruled out any cellular atypia,
Correspondence: Silonie Sachdeva, MD, Consultant Dermatologist, Carolena Skin, Laser \& Research Centre, Jalandhar Punjab-144022, India.

E-mail: siloniederm@yahoo.com

Key words: ulcerated, epitheloid, hemangioendothelioma.

Conflict of interest: the author has no conflict of interest to disclose.

Received for publication: 21 May 2011. Accepted for publication: 9 August 2011.

This work is licensed under a Creative Commons Attribution NonCommercial 3.0 License (CC BYNC 3.0).

CCopyright S. Sachdeva, 2011

Licensee PAGEPress, Italy

Dermatology Reports 2011; 3:e17

doi:10.4081/dr.2011.e17

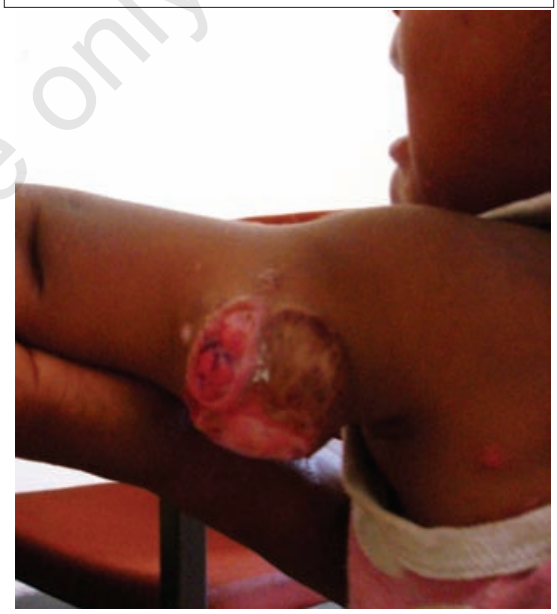

Figure 1. A well defined, large sized swelling, round shaped, dusky red in color with ulceration on lateral side of left upper arm.

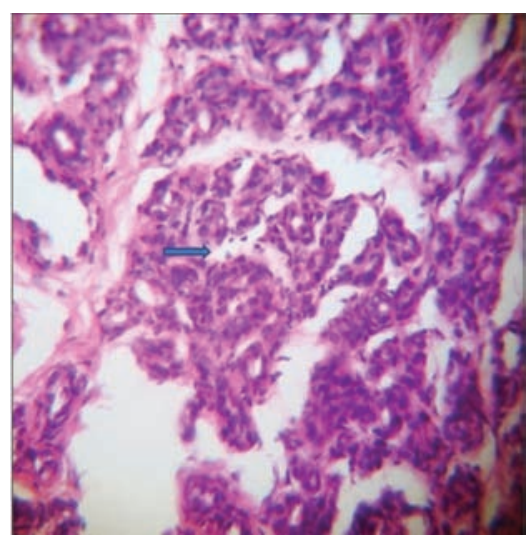

Figure 2. Histopathology with H \& E stain, 100x showing focal areas of infiltrative vague lobules of predominantly spindle cells in deeper dermis with small sized vascular channels lined by plump endothelial cells. There are foci of intravascular endothelial proliferation with the adjacent areas showing capillary proliferation with hobnail appearance. (See arrow) 
mitotic activity or necrosis. The tumor was positive for the endothelial markers CD31, CD34 which confirmed the histological and clinical diagnosis. Besides these endothelial markers, it is advised that analysis of Factor VIIIrAg and alpha smooth-muscle actin which are also important immunohistochemical markers for cutaneous EHE should be done wherever the facility is available. Differential diagnosis of cutaneous epithelioid hemangioendothelioma include epithelioid angiosarcoma which on histological examination shows more nuclear atypia and mitotic activity, more necrosis than EHE and an interstitial or sinusoidal growth pattern in its peripheral areas. The specific interest of our case is the clinical presentation of this tumor at an age of 8 months, which has not been previ- ously reported in literature. Also, we want to emphasize that early detection and removal of tumor can lessen the chances of tumor turning malignant and can be life saving.

\section{References}

1. Weiss SW, Enzinger FM. Epithelioid hemangioendothelioma. A vascular tumor often mistaken for a carcinoma. Cancer 1982;50:970-81.

2. Resnik KS, Kantor GR, Spielvogel RL, Ryan E. Cutaneous epithelioid hemangioendothelioma without systemic involvment. Am J Dermatopathol 1993;15:272-76.
3. Polk P, Webb JM. Isolated cutaneous epithelioid hemangioendothelioma. J Am Acad Dermatol 1997;36:1026-28.

4. Quante M, Patel NK, Hill S, et al. Epithelioid hemangioendothelioma presenting in the Skin. A clinicopathologic study of eight cases 1998;20:541-46.

5. Zhang W, He J, Wang J, et al. Ulcerated epithelioid hemangioendothelioma of the right armpit in childhood. J Pediatr Hematol Oncol 2009;31:595-98.

6. Forschner A, Harms D, Metzler G, et al. Ulcerated epithelioid hemangioendothelioma of the foot in childhood. J Am Acad Dermatol 2003;49:113-6.

7. Grézard P, Balme B, Ceruse P, et al. Ulcerated cutaneous epithelioid hemangioendothelioma. Eur J Dermatol 1999;9:487-90. 